Elites y artesanos a través del pensamiento politico intelectual

\title{
Elites y artesanos a través del pensamiento politico intelectual de John Adams y Thomas Paine
}

\section{Elites and artisans through the intellectual political thought of John Adams and Thomas Paine}

JOAQUINA DE DONATO LOZANO

Instituto Interdisciplinario de Estudios e Investigaciones de América Latina

Facultad de Filosofia y Letras

Universidad de Buenos Aires

joaquina.dedonato92@gmail.com

\section{RESUMEN}

La independencia de los Estados Unidos fue el resultado de un altisonante proceso culminado en 1776 , donde lo que estaba en disputa no era simplemente una lucha contra la corona británica sino también una puja interna por decidir quién y cómo debía gobernarse una vez que la independencia fuese alcanzada. Todos los sectores sociales involucrados volcaron en el proceso revolucionario intereses y aspiraciones, y actuaron con el deliberado propósito de modificar su situación presente. Para las élites coloniales, la independencia debía tratarse de un "ordenado" traspaso de mando entre clases gobernantes. Para los artesanos, significaba la ampliación de derechos políticos y una distribución económica más equitativa. El presente trabajo se propone analizar esta dinámica por medio de los panfletos que dos importantes figuras del proceso revolucionario, John Adams y Thomas Paine, publicaron en 1776. Consideramos que sus escritos constituyen una ventana de oportunidad hacia lo que la independencia significó para las clases sociales en disputa. Y al mismo tiempo, nos sugieren la posibilidad de reconstruir la herencia cultural a partir de la cual elites y artesanos interpretaron la independencia y construyeron su accionar.

Palabras clave: independencia; elites coloniales; artesanos; revolución; lucha de clases

ABSTRACT 
Independence from the United States was the result of a heated process culminating in 1776 , where what was at stake was not simply a fight against the British crown but also an internal struggle to decide who should be governed -and how- once independence was achieved. All the social sectors involved poured their interests and aspirations into the revolutionary process, and acted with the deliberate aim of changing their present situation. For the colonial elites, independence was to be an "orderly" transfer of command between ruling classes. For the artisans, it meant the extension of political rights and a more equitable economic distribution. The present paper seeks to analyse this dynamic through the pamphlets published in 1776 by two important figures in the revolutionary process, John Adams and Thomas Paine. We consider their writings to be a window of opportunity on what independence meant for the social classes in dispute. And at the same time, they suggest to us the possibility of reconstructing the cultural heritage from which elites and artisans interpreted independence and built their action.

Keywords: independence; colonial elites; artisans; revolution; class struggle

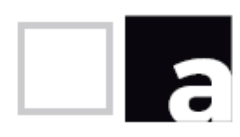

\section{Introducción}

Era mediados de abril de 1776 cuando John Adams autorizó la publicación, en forma de panfleto, de una carta dirigida a George Wythe de Virginia, donde sugería (para las entonces insurgentes colonias de Norteamérica) la adopción de un sistema de gobierno republicano, y delineaba las pautas a seguir para su implementación. A pocas semanas de la publicación, Adams recibió una visita de Thomas Paine, un artesano inglés devenido en escritor, recién llegado a Filadelfia y autor del exitoso panfleto a favor de la independencia, Sentido común. Según describió Adams en su diario, Paine se había acercado para reprenderlo por la publicación de Pensamientos sobre la forma de gobierno aduciendo que "temía que hiciese mal" y que era "repugnante" para con el plan de gobierno que él había propuesto en Sentido común. "Le dije que tenía razón, era repugnante" -continúa Adams- "y por esa razón lo había escrito y consentido a que se publicara; porque yo tenía tanto miedo a su trabajo como él al mío" (Adams, 1851).

Se trata de una anécdota memorable y que despierta preguntas concernientes a la etapa del proceso revolucionario estadounidense comprendida entre 1765 y 1776. ¿Por qué a Paine le preocupaban las ideas esbozadas en Pensamientos sobre la

\section{anuario.}


forma de gobierno y viceversa? ¿Por qué Adams confesaría temerle a alguien que luego describiría como un "mestizo entre puerco y cachorro" (citado en Fruchtman, 2009) cuyo estilo de escritura era "propio de un prisionero de Newgate"? 1

Esto además es interesante si se tiene en cuenta que para 1776, ambos hombres tenian más razones para concordar que para estar en desacuerdo. Tanto Adams como Paine eran férreos defensores de la independencia de las colonias del dominio británico y se pronunciaban en contra de quienes mantenían la "ilusión" de una reconciliación. Más importante aún, ambos defendian la instauración de un gobierno republicano para las colonias. Y sin embargo, pese las coincidencias, que más que separar debieron haber estrechado el vínculo entre ellos, para John Adams, Paine era un "desastroso meteorito" que había impactado Filadelfia (Adams, 1851), un "insolente blasfemo de todo aquello que es sagrado" cuya obra, Sentido común, no era más que una "pobre, ignorante, maliciosa, miope y crapulosa masa" (citado en Kaye, 2007).

¿Cuál es la mejor forma de explicar semejante animosidad? Desde ya se trataban de personalidades sumamente discordantes. Ni la modestia ni el disimulo estaban entre sus virtudes. Además, poseían ambos un carácter fuerte y temperamento excitable. ${ }^{2}$ Pero más que como un conflicto entre personalidades divergentes, el intercambio entre Adams y Paine es mejor entendido cuando se lo enmarca dentro de la dinámica del proceso revolucionario estadounidense. Cuando analizado desde esa perspectiva, la anécdota se torna relevante ya que se la puede entender como una expresión de la lucha que se estaba librando entre aquellas clases abocadas a limitar la democratización de prácticas políticas y las que buscaban extenderlas y profundizarlas. Dicho de otra forma, a lo que Adams temía era al "radicalismo que Paine amenazaba con desatar" (Kaye, 2007). Y sus intentos por desacreditarlo se comprenden mejor cuando son vistos como un esfuerzo por desestimar sus proyecciones democráticas más que como una venganza personal producto de los celos (Larkin, 2005).

La lucha por la independencia en los Estados Unidos fue un proceso altisonante y plagado de contradicciones. Como planteó hace ya varias décadas el historiador Carl L. Becker, la revolución no se trató simplemente de una lucha por parte de las colonias norteamericanas para librarse del imperio británico, sino que también incluyó una disputa interna entre sus protagonistas sobre quién debía gobernar y cómo debía gobernarse una vez que la independencia fuese alcanzada. La revolución fue mucho más compleja que la unión de las colonias contra un enemigo

1 Conocida cárcel de Londres.

2 Para un análisis detallado de las personalidades de Adams y Paine ver: Fruchtman Jr, Jack (1996). Thomas Paine: Apostle of Freedom, Village Station: Four Walls Eight Windows y McCullough, David (2001). John Adams, Nueva York: Simon \& Schuster. 
común porque quienes la protagonizaron se incorporaron a ella cargando una serie de ideas, sueños y aspiraciones que se nutrian de experiencias y tradiciones previas al desencadenamiento del conflicto (Nash, 2006). Es por ello que la misma pudo ser radical y conservadora al mismo tiempo (Young, 2006).

Todos los sectores sociales que participaron en la revolución, desde comerciantes y plantadores esclavistas hasta artesanos, granjeros y marineros (por solo nombrar a algunos), decidieron el bando al cual se incorporaron en base a una serie de nociones heredadas, ancladas en la percepción de su experiencia cotidiana (Nash, 1979). En un principio, esto permitió a las elites coloniales ${ }^{3}$ whig $^{4}$ encauzar la expresión popular hacia formas de participación que no ponían en riesgo su rol como líderes del proceso revolucionario. Pero a medida que la crisis llegaba a su punto álgido, las clases trabajadoras ${ }^{5}$ comenzaron a profundizar una consciencia de intereses no siempre a tono con aquellos de los whig. En un sinnúmero de ocasiones esto trajo por resultado que dichos sectores terminaran poniéndose a la cabeza de la lucha revolucionaria y empujando a las élites coloniales hacia propuestas y formas de lucha mucho más radicales que las que éstas consideraban aconsejables, como cuando granjeros y artesanos del condado de Worcester se autoconvocaron para crear una "convención" que expulsó a los jueces nombrados por la Corona y asumió las tareas legislativas del condado (Raphael, 2001).

Así, desde 1774, la crisis revolucionaria profundizó en las colonias un marcado conflicto de clases. El conflicto entre Paine y Adams debe comprenderse a la luz de esta dinámica. La lectura que los autores hicieron de la lucha revolucionaria, sus proyecciones acerca de la independencia y la forma de gobierno que vislumbraron para las colonias, fueron producto tanto de tradiciones y culturas específicas como de la particularidad del contexto en el que se hallaron inmersos. Los argumentos y

\footnotetext{
3 Por élites coloniales o simplemente "elites" se comprende tanto a las del Norte como a las del Sur. Cuando utilizado en plural en el presente escrito engloba tanto a los grandes comerciantes de los centros portuarios y plantadores esclavistas sureños, como a abogados, miembros del clero anglicano y a quienes ocupaban los puestos más altos del gobierno colonial (Nash, 2006).

4 Término contemporáneo que refiere a los individuos más antibritánicos, a quienes protestaron contra las medidas británicas y trataron de llevar adelante concretas medidas de resistencia y movilización popular. El término deriva del movimiento político que, durante la Revolución Gloriosa ocurrida en 1688 en Gran Bretaña, derrocó a Jacobo II y aseguró la supremacía del Parlamento en el marco de una monarquía constitucional. Entre los principales postulados de la ideología whig se encontraba la defensa de una división de poderes dentro de un gobierno electo por propietarios, la igualdad ante la ley y la libertad para comerciar sin restricciones estatales. Para las élites americanas del siglo XVIII, esta ideología simbolizó el derecho a oponerse a la "arbitrariedad" de las regulaciones imperiales, de ahí que el término whig pasó a ser sinónimo de "patriota".

5 Clases trabajadoras o en inglés Laboring classes es el término que los historiadores norteamericanos pertenecientes a la New Labor History utilizan para referir al conjunto de trabajadores coloniales de los siglos XVII y XVIII. El término enfatiza el plural para englobar una heterogeneidad de trabajadores diferenciados por calificación y status, y también para establecer una diferencia con la clase obrera en formación en Estados Unidos a partir del siglo XIX. Junto con granjeros, siervos, esclavos, marineros y trabajadores no calificados, los artesanos son incluidos dentro de las clases trabajadoras. A partir de este momento, la categoría será empleada junto con "sectores populares" cuando se haga referencia al conjunto de trabajadores coloniales, no sólo a los artesanos, ya que todos ellos vivieron un despertar político durante el proceso revolucionario y se involucraron en él activamente.
} 
retórica que conforman ambos escritos son una sintesis (inconclusa)

de la percepción personal, la cultura y la clase a la cual sus autores pertenecian. Las similitudes que pueden señalarse entre ambos se desprenden de los intereses que tanto elites coloniales whig como artesanos compartieron hacia la independencia. Y sus discrepancias reflejan la disputa entre dichos sectores sobre las posibilidades que se abririan una vez que la revolución culminase. Planteada la cuestión, lo que sigue es un intento por analizar Sentido común y Pensamientos sobre la forma de gobierno como expresión del mencionado conflicto de clases. Esto es posible en tanto entendamos que las propuestas y percepciones que tuvieron los autores se vieron atravesadas por una herencia cultural específica, que podía tener sus puntos en común, pero que en la mayoría de los casos devino en posturas contrapuestas. A su vez, el éxito que tanto Adams como Paine cosecharon dentro las clases a las cuales pertenecieron, permite establecer una correlación entre las propuestas políticas delineadas en los panfletos y sentimientos de clase específicos. El hecho de que élites whig ${ }^{6}$ y artesanos hayan percibido lo que Adams y Paine escribieron como propio, adoptándolos como voceros de sus intereses, y de que hayan hecho uso de ello a la hora de elaborar demandas y adoptar medidas, nos habla de la circulación de una cultura y de formas de expresión determinadas.

Con esto no pretendemos establecer una relación mecánica entre un individuo y su clase. Si lo hiciéramos, estariamos aceptando la posibilidad de que cualquier artesano podria haber sido tan prolífico con la pluma como lo fue Paine, o que cualquier whig podria haber escrito Pensamientos sobre la forma de gobierno. Y la evidencia histórica apunta hacia un terreno contrario. De lo que se trata, entonces, es de rastrear el terreno cultural común que atraviesa las propuestas de ambos panfletos. Así, no pretendemos homogeneizar experiencias, sino abrirnos a la posibilidad de que, pese a la heterogeneidad de las mismas, los sujetos involucrados pudieron comprender lo que Adams y Paine escribieron y concluir que evocaban sus propios intereses y aspiraciones. De lo que se trata es de plantear una articulación dinámica entre pautas culturales comunes a determinado sector social y su traducción en prácticas políticas concretas.

Todo esto nos abre la posibilidad de utilizar los panfletos escritos por estos autores para colaborar a construir una visión integral de la turbulencia política del período revolucionario. La escasa distancia entre la producción de ambos documentos (apenas un mes) ${ }^{7}$ y la coincidencia en los fines que motivaron a los autores a su publicación, nos inspira a elaborar un relato simultáneo desde dos sectores sociales

6 John Adams formó parte y supo sintetizar los intereses de la elite norteña. Sin embargo, aquí y a lo largo del escrito, se empleará también el plural dado que a partir de la crisis revolucionaria -y por lo menos hasta fines de la década de 1780-, hubo una concordancia de intereses, tanto políticos como económicos, entre las élites del Norte y las del Sur (Lynd, 1967). De hecho, quien pide a Adams el boceto de su plan de gobierno es miembro de la élite de Virginia.

7 Sentido Común se publica en enero de 1776 mientras que Adams escribe las cartas que luego serán publicadas como Pensamientos sobre la forma de gobierno entre febrero y marzo de 1776. 
ubicados en extremos opuestos de la jerarquía social. En este sentido, se aclara que la prioridad de esta producción tiende hacia las clases menos favorecidas en tanto hacerlos hablar y conocer sus aspiraciones y deseos se torna más complejo dada la "invisibilidad histórica" que solo hace pocas décadas comenzó a corregirse. En el caso de Adams (y de las elites coloniales en su conjunto), contamos no solo con sus publicaciones sino también con todo un conjunto de documentos públicos y privados que nos facilitan comprender que pensaron y sintieron a medida que los acontecimientos se desenvolvieron. En el caso de las clases trabajadoras -y de los artesanos en particular- estamos en obvia desventaja. Estos sujetos no carecian de la capacidad de hablar o de expresarse, pero su discurso y accionar tendió a no ser registrado para la posteridad y cuando lo hizo fue a través de la subjetividad de los estratos superiores de la sociedad. Paine es una ventana de oportunidad hacia ellos y procuraremos ponerlo al servicio de tales fines.

\section{Elites y artesanos en vísperas de la independencia (1774-1776)}

En marzo de 1765 el Parlamento británico autorizó la Ley de Sellos para sus trece colonias en Norteamérica con el objetivo de que estas ayudaran a pagar por las tropas estacionadas en su territorio luego de finalizada la Guerra de los Siete Años. ${ }^{8}$ El nuevo impuesto desató una oleada de oposición entre los colonos la cual llegó a su punto álgido nueve años después, en $1774 .{ }^{9} \mathrm{~A}$ partir de ese momento, lo que había comenzado como una resistencia contra las distintas políticas de recaudación británicas, bajo un contexto de depresión económica (producto de la guerra) adquirió las características de un movimiento revolucionario.

Se trató de un proceso lento pero constante. Los colonos no se volvieron revolucionarios de la noche a la mañana pero la obstinación del Parlamento británico por seguir adelante con sus nuevas medidas impositivas sin recurrir a canales que acallaran el conflicto, colaboró a profundizar la crisis hasta tornarla irreversible. Más importante aún, las acciones colectivas que moldearon la

\footnotetext{
8 La Guerra de los Siete años, disputada principalmente entre Gran Bretaña y Francia entre 1756 y 1763, produjo en las colonias británicas en América una profunda depresión económica. La guerra aceleró un proceso de concentración de riqueza en favor de las élites coloniales y resultó en un marcado aumento en los índices de pobreza, sobre todo en los centros portuarios norteños. La crisis recayó con mayor énfasis sobre las clases trabajadoras urbanas y se vio reflejada en la pérdida de propiedad, desempleo y escasez de oportunidades para estos sectores (Nash, 1976).

9 A la Ley de Sellos de 1765 le sucedió la Ley de Acuartelamiento también en 1765, la cual obligaba a alojar y alimentar a las tropas británicas que llegaban de la Metrópoli, las Leyes de Townshend en 1767 (nuevos impuestos de diverso tipo), la Ley del Té en 1773, que permitió a la Compañía Británica de las Indias Orientales monopolizar la exportación de té a las 13 colonias americanas, y las Leyes Coercitivas en 1774, las cuales forzaron el cierre del puerto de Boston hasta que la Corona fuera resarcida por la destrucción del té ocurrida en respuesta a la ley de 1773. Todas estas leyes significaron para las colonias, no solo una pérdida de autonomía sino también que se restringiera su desarrollo económico e impidiera salir de la depresión económica traída por la Guerra de los Siete Años.
} 
resistencia posibilitaron la emergencia de nuevas formas de conciencia entre los sectores sociales involucrados.

En ninguno ese proceso fue tan destacable como entre las clases trabajadoras, en particular los artesanos. Las élites coloniales ya conservaban y reproducian una tradición que las definía, en base a su educación y riqueza, como la legítima clase dirigente a nivel politico por lo que no hizo falta que crearan organizaciones como los Hijos de la Libertad $^{10}$ para que tomaran noción de sí mismas en esos términos.

En los sectores populares, en cambio, se trató de un proceso mucho más disruptivo, ya que la concientización de su relevancia política llevó aparejada una crítica al orden establecido. Al reclamar su derecho a intervenir en el campo político y plantearse en pie de igualdad para con sus "mejores", artesanos y demás trabajadores no solo estaban rompiendo con la imagen dúctil e infantil que las élites solían usar para describirlos, sino que también estaban destruyendo la deferencia que caracterizaba al trato entre clases.

El movimiento de no importación ocurrido entre 1768 y 1774 jugó un rol clave en esta politización. En particular entre artesanos, el éxito de los boicots contra las manufacturas británicas les permitió desarrollar sentimientos de clase vinculados a la utilidad social de sus oficios y a sus aspiraciones por ser "independientes", esto es, la capacidad de subsistir honesta y cómodamente por sus propios medios sin tener que recurrir a la caridad. Los boicots no solo ayudaron a resaltar la relevancia del artesano como productor dentro de una comunidad, sino que también los estimuló a percibir a la sociedad dividida entre aquellos que vivian de su propio trabajo y aquellos que se beneficiaban con el trabajo ajeno. Esto colaboró a corromper lazos verticales con los estratos superiores y a ampliar lazos horizontales, tanto dentro como fuera de la "hermandad del oficio", hecho que provocó que "las aspiraciones tradicionales de los artesanos por lograr una "independencia" a nivel personal se vieran entrelazadas con el movimiento para volver al país independiente de las manufacturas británicas” (Young, 2006).

Llegado mediados de 1774, cuando el recién formado Congreso Continental llamó a la creación de comités a lo largo de las colonias para garantizar el boicot al comercio británico, los artesanos ya habian emergido como un sector consciente de sus intereses y con un perfil profundamente antibritánico (Foner, 1976). Para ese año, por lo tanto, la amenaza de "democracia" que había estado implícita en la participación popular contra las imposiciones de la Corona se había vuelto explícita. A partir de ese momento, sea agrupados en comités, milicias o

\footnotetext{
10 Se conoce como Hijos de la Libertad a una serie de comités locales a través de los cuales se organizó la resistencia a la Ley de Sellos (1765) y a las subsecuentes medidas del Parlamento británico por afianzar sus dominios coloniales. En su mayoria, estas asociaciones estaban compuestas por aquellos líderes de las elites coloniales whig ubicadas en los estratos medios de la sociedad colonial.
} 
presionando por nominar gente de sus filas para los cargos gubernamentales, los artesanos se plantaron ante las élites como sus iguales y jugaron un rol significativo en la politización y organización de las demás clases trabajadoras urbanas.

Quienes retenían el poder político y económico en las colonias observaron este proceso con creciente inquietud. Un ejemplo de ello es el testimonio del joven conservador Gouverneur Morris, miembro de una de las familias de mayor status en Nueva York y uno de los futuros redactores de la Constitución:

La muchedumbre comienza a pensar y razonar. ¡Pobres reptiles! Para ellos esta es una mañana primaveral, están luchando por abandonar los pantanos invernales, disfrutan del sol, y para cuando llegue el atardecer morderán, podemos estar seguros de ello. La gentry comienza a temerles... Puedo verlo, puedo verlo con miedo y temblor, que si la disputa con Gran Bretaña continúa, estaremos bajo el peor de todos los posibles dominios; estaremos bajo el dominio de una revoltosa multitud (citado en Lynd, 1967: 89).

Pero la "muchedumbre" no solo fue un motivo de preocupación para los whigs conservadores. También lo fue para los más populares, porque si bien pertenecer a los estratos "medios" de la sociedad colonial les facilitaba sociabilizar con las clases trabajadoras y captar su apoyo para participar en los actos de resistencia a Gran Bretaña, al mismo tiempo les impuso la tarea de contener la presión que ejercían los trabajadores desde abajo. Estos grupos fueron radicales en su retórica y en su actuar, sólo cuando se trató de organizar alguna medida contra las políticas del Parlamento. El resto del tiempo lucharon por controlar y desestimar los reclamos populares. A partir de 1774, esto se tornó cada vez más dificil, ya que su rol como dirigentes comenzó a ser disputado por artesanos y demás mecánicos ${ }^{11}$ que ahora poseían organizaciones autónomas a través de las cuales plantear sus reclamos y organizar actos de resistencia. ${ }^{12}$

Las batallas de Lexington y Concord de abril de 1775 fueron un punto de inflexión para las clases trabajadoras, que entonces concibieron que el único desenlace viable para el conflicto (que ya llevaba una década de duración) era la independencia. Para que esto fuese formulado de manera explícita hubo que esperar a 1776 pero, en el interín, "autoridades duales" surgieron en varias jurisdicciones, es decir, organizaciones de granjeros y artesanos que se negaron a reconocer la autoridad británica e impidieron a los funcionarios reales el ejercicio de sus tareas legislativas y administrativas. En algunas zonas, como en el condado de Worcester, su asamblea inclusive emitió una declaración que absolvía a sus miembros de acatar toda ley emitida por la Corona y proclamó que a partir de ese

11 Término contemporáneo con el que se englobaba a todo aquel cuya subsistencia dependía del trabajo manual.

12 Además de los boicots a las importaciones de la Metrópoli, las clases trabajadoras protagonizaron protestas callejeras contra las autoridades británicas (en muchos casos forzando su renuncia) y se vieron envueltas en diversas confrontaciones contra las tropas estacionadas en las colonias. 
momento "todos los oficiales serian dependientes del sufragio del pueblo". Así, como plantea Ray Raphael (2001), la independencia fue "un hecho" para la vida de la gente común antes de que la Declaración de Independencia fuese redactada.

Terratenientes y grandes comerciantes, por el contrario, procedieron con mayor cautela. Aproximadamente desde mediados del siglo XVII, estos grupos fueron los directos beneficiarios de un lento pero ininterrumpido proceso de concentración de la riqueza en las colonias. Para fines de la década de 1760, sin embargo, este proceso fue puesto en jaque por las necesidades de un imperio en vísperas de su revolución industrial. La independencia, las élites consideraban, bien podía librarlas de las restricciones de la Corona y despejar el camino para consolidarlas como clase económica y políticamente dominante. Pero no menos cierto era, como planteó Morris, que podía desencadenar su propia ruina si terminaba dejándolas a merced de una "revoltosa multitud", por lo que la gran mayoría de ellas evaluó que era más prudente insistir en la reconciliación que abrir la posibilidad a un despertar democrático en las colonias (Foner, 1945).

Fue en este contexto de ebullición popular, y de los esfuerzos de los whig por contenerla, que Thomas Paine publicó Sentido común, en enero de 1776.

\section{Un "meteorito" llega a Filadelfia}

Thomas Paine, oriundo de Thetford, era hijo de un artesano cuáquero y de madre anglicana. Hasta los 37 años de edad vivió en Inglaterra, mudándose intermitentemente de ciudad en ciudad y de trabajo en trabajo. En 1774, luego de ser despedido de su cargo como recaudador de impuestos aduaneros y con cartas de recomendación de Benjamín Franklin, emigró a Pensilvania, una de las principales colonias británicas en Norteamérica. Menos de un año después de su llegada, Paine escribió uno de los panfletos más leídos de la América colonial: Sentido común.

El panfleto se publicó por primera vez en Filadelfia y en apenas meses se convirtió "en el best seller del siglo" (Fruchtman, 1996). No sujeto a derechos de autor, se estima que fueron vendidas alrededor de 150.000 copias en más de treinta y cinco ediciones (Young, 2006). Pero es probable que su difusión haya sido aún más amplia si tenemos en cuenta ediciones clandestinas, préstamos y lecturas públicas en tabernas y talleres.

Según el historiador Alfred Young (2006), la popularidad del panfleto se debió a que logró poner en palabras y sintetizar en un lenguaje sencillo y accesible el deseo no 
explícito de las clases populares hacia la independencia. Pero esto no fue todo lo que hizo. En una época en la que artesanos, granjeros y trabajadores estaban bregando por construir espacios y organizaciones donde sus reclamos se vieran atendidos, Sentido común logró hacer orbitar a toda esta multitud de acciones alrededor de un objetivo común: la independencia de las colonias y la instauración de un gobierno republicano. Es decir, transformó todas esas experiencias en un tipo de formulación política que las élites no podían desatender ni disfrazar por los "irracionales impulsos" de la "muchedumbre". De esta forma, Paine encauzó y legitimó su lucha dentro de un fin que era plausible, concreto y que, en tanto trascendía intereses individuales, podía ser compartido por amplios sectores populares.

Sentido común gira en torno a tres ejes en constante interrelación. En primer lugar, el llamado a una inmediata independencia y la necesaria unión entre las colonias para alcanzarla. En segundo lugar, la defensa del republicanismo como única forma de gobierno capaz de asegurar los derechos y libertades de todos los hombres. Por último, la confianza en que la gente corriente, al participar activamente en el campo político, era la más apropiada para garantizar el fin último de todo buen gobierno: la seguridad de la sociedad (Young, 2006).

Para lograr estos objetivos era menester que los colonos se animaran a comprender las falacias escondidas tras los lazos que los mantenian leales a Gran Bretaña. Para ello, primero había que desmontar los argumentos (arraigados en tradiciones y costumbres de larga data) a favor de la monarquía, el rey y la constitución inglesa, así como también desestimar toda postura a favor de la reconciliación y las convenciones acerca de la incapacidad de las colonias por subsistir sin el amparo de la Corona.

Dado que creía que la verdad era simple y universal, y que cualquier hombre podía acceder a ella en tanto apelara a la razón que Dios había depositado en él, Paine se encargó de construir una retórica con la que el lector fuera capaz de inferir las conclusiones a partir de los argumentos presentados, inclusive antes de que él las hubiera hecho explícitas (Larkin, 2005). Y se valió de un lenguaje sencillo y directo que cualquiera, inclusive aquel desprovisto de educación, podía entender. El resultado fue la creación de un nuevo lenguaje político, destinado a alcanzar una audiencia masiva y con la capacidad de empoderar a sus lectores al presentar una serie de argumentos complejos y sofisticados, que antes sólo podian comprender las élites educadas, como hechos sencillos y entendibles para cualquiera (Foner, 1976).

¿Cómo podemos explicar que Paine, un inmigrante recién llegado con prácticamente ninguna experiencia previa con la pluma, haya logrado modernizar los términos del debate colonial de la época? En primer lugar, es importante tener en cuenta que hasta ese momento, los escritores eran (casi exclusivamente) de las clases altas por lo que seguían enmarcando la disputa con Gran Bretaña en una 
cuestión de autonomía colonial, es decir, en cuestiones sobre impuestos y una posible representación en el Parlamento (Pozzi, 2017). Paine, en cambio, provenía del mismo sector social que su principal audiencia: los artesanos. Por lo tanto, su lenguaje fue revolucionario porque estuvo anclado en la experiencia cotidiana propia y la de sus lectores; no solo se valió de él para hablar a favor de la democracia; su lenguaje en sí mismo era democrático.

Por otro lado, Paine llegó a Filadelfia en noviembre de 1774 y para enero de 1776 ya había publicado Sentido común. El estrecho tramo entre un evento y el otro nos sugiere que muchas de las ideas esbozadas en el panfleto venían, desde hacía tiempo, perfilándose en su cabeza. Pero dado que esas ideas sólo parecen haber florecido tras asentarse Paine en Filadelfia, sería significativo responder, entonces, ¿qué cambió en él tras su arribo?

Para proponer una posible respuesta, partimos de la premisa de que la experiencia cotidiana es la base de la politización de todo individuo (Mastrángelo, 2009). La situación política de Filadelfia fascinó a Paine. A apenas semanas de su llegada, el primer Congreso Continental resolvió reanudar el boicot a los bienes ingleses y poco después, Lexington y Concord. Thomas Paine provenía de una tradición inglesa de rebelión y la movilización de trabajadores formando comités y milicias debe haber reafirmado en él el convencimiento del derecho que la gente común tenía de vivir como ciudadanos libres. Más aún, comparado con las condiciones materiales en su tierra natal, América se le presentaba como una tierra próspera donde la pobreza era escasa y el acceso a una independencia económica, posible.

Filadelfia era para Paine la oportunidad de un nuevo comienzo y este nuevo comienzo estaba siendo estropeado por el mismo imperio que no le había permitido vivir dignamente ni como artesano ni como trabajador en su tierra natal. Podriamos decir, entonces, que asistimos a un proceso dialéctico en el que la politización que Paine experimentó al vivenciar el accionar de las clases trabajadoras en Filadelfia fue puesta en juego junto con sus propias experiencias y tradiciones para producir Sentido común.

Pero esto no agota la cuestión. El éxito de Sentido común, como advirtió Eric Hobsbawm (1999), es "un problema histórico" y decir que Paine formaba parte de las clases trabajadoras no resuelve el problema, meramente nos habilita un terreno firme desde el cual contemplarlo. ${ }^{13}$ Postular que un individuo forma parte de una clase social no sólo implica poder ubicarlo dentro de un determinado proceso

\footnotetext{
13 Entendemos que Paine debe quedar incluido dentro de las clases trabajadoras ya que, si bien luego de su llegada a América no volvió a ejercer como artesano y de ahí en más se reivindicó siempre como escritor, tanto sus condiciones materiales como la cultura a partir de la cual comprendió su experiencia cotidiana, su ocupación y su status social, vuelve inapropiado considerarlo como miembro de la elites coloniales.
} 
productivo y dentro de un contexto determinado. También implica advertir que su identidad está vinculada a la percepción que ese individuo tiene de su experiencia como trabajador, y que la misma está anclada en una serie de significaciones culturales heredadas.

En el caso de Paine y los artesanos, el entendimiento de las relaciones sociales cotidianas y de la turbulencia política teniendo lugar, estaba anclado en una "cultura plebeya" que se nutría de una serie de tradiciones provenientes de la temprana modernidad inglesa y que habian sido resignificadas bajo la experiencia revolucionaria de 1640 . Uno de los pilares distintivos de esta cultura era el orgullo que los mecánicos derivaban de la utilidad y responsabilidad social de su oficio dentro de una comunidad, y la concepción del trabajo como una forma de propiedad.

A partir de 1640, esta tradición, que circulaba oralmente en el ámbito de talleres, barrios y tabernas inglesas, se tradujo por primera vez en una formulación politica explícita. Al fundirse con el activismo político de los levellers y expresarse públicamente durante los Debates de Putney, esta tradición no sólo se radicalizó sino que también se sofisticó. ${ }^{14}$ Como subyace del Acuerdo del Pueblo esbozado por los levellers, el eje seguía siendo la concepción de una forma de vida libre y comunal conseguida por medio del trabajo, pero ahora esto se plasmaba en demandas concretas: la expansión de la representación parlamentaria, la abolición de la monarquía y la búsqueda por una distribución económica más equitativa (Schultz, 1993).

Si bien este movimiento radical falló en su infancia y la Restauración de la monarquía en 1660 lo obligó a "vivir una existencia clandestina" (Schultz, 1993), según Peter Linebaugh (1982): "las fuerzas de la discusión ocurrida en Putney se pulverizaron y esparcieron a los cuatro vientos". Esto es, muchos individuos que habían sido parte de los grupos radicales formados durante la revolución inglesa acabaron emigrando. Muchos de ellos lo hicieron hacia las colonias británicas en América del Norte. Esto permitió la transmisión de información e ideas entre distintos grupos de trabajadores, así como la posibilidad de que dichas ideas fuesen resignificadas a la luz de nuevas relaciones sociales (Rediker: 1982). Por lo tanto, las formas de organización y la coherencia ideológica alcanzada en Putney pueden no haberse mantenido en el Nuevo Mundo pero la experiencia revolucionaria permaneció impresa en la memoria de las clases trabajadoras (Linebaugh, 1982).

\footnotetext{
14 Se conoce como Debates de Putney a una serie de discusiones ocurridas dentro del New Model Army en el año 1647 durante la Guerra Civil desencadenada por la confrontación entre el rey Carlos I y su Parlamento. Para 1647, las bases del New Model Army comenzaron a radicalizarse y a expresar una serie de exigencias políticas frente al Parlamento británico que se condensaron, luego de los debates en la iglesia de Putney, en el Acuerdo del Pueblo de 1649. Entre sus principales puntos el acuerdo incluía la demanda por la abolición de la monarquía y la Cámara de los Lores, la expansión del sufragio, tolerancia religiosa, abolir la privatización de los terrenos comunales y también del diezmo eclesíastico.
} 
Esta tradición volvió a volcarse hacia un accionar concreto durante el proceso revolucionario estadounidense. El mismo contexto fue el que estimuló a Thomas Paine a escribir Sentido común. Su retórica, las ideas acerca del gobierno y la forma de concebir el trabajo y la sociedad, están nutridas por los componentes de esta misma tradición radical. Más importante aún, la popularidad que este nuevo lenguaje político cosechó entre las clases trabajadoras, y en particular entre los artesanos, es prueba de la persistencia de estas ideas en la memoria popular y de la circulación de las mismas en el mundo atlántico (Lynd, 1968).

Más adelante nos detendremos en el contenido de las ideas de Sentido común y los puntos de contacto entre estas y la tradición radical. Por el momento quisiéramos señalar que tal y como ocurrió en Putney, al darle Paine una formulación política explícita, esta tradición se sofisticó y complejizó. En Sentido común, Paine defendió el republicanismo como el mejor sistema de gobierno posible y propuso una legislatura de cámara única para cada colonia junto con elecciones anuales y abiertas para todos. A su vez, llamó a la redacción de una "constitución" ("Carta de las Colonias Unidas") la cual presidiera a la elección de cualquier representante (Foner, 1945).

Estas propuestas (base de lo que podriamos catalogar como "democracia radical") dispararon las aspiraciones de las clases trabajadoras a lo largo y ancho de las colonias. Su popularidad y difusión no es lo único que nos lo sugiere. Hubo una apropiación que los artesanos hicieron de Paine, inferible a partir de las acciones de estos grupos en los meses anteriores a la Declaración de la Independencia. ${ }^{15}$ Brindis en nombre de Sentido común comenzaron a aflorar entre organizaciones artesanas de todos los estratos. Cuando el Comité General de Mecánicos en Nueva York se enteró que el editor Samuel Loudon estaba a punto de publicar un panfleto hostil a Sentido común, sus miembros secuestraron la imprenta y quemaron la tienda. En mayo de 1776, ese mismo comité demandó la ratificación popular de una constitución para Nueva York alegando que quizás "no todos los hombres estaban calificados para redactar constituciones" pero tenían el suficiente "sentido común" para juzgarlas (citado en Lynd, 1967).

Nueva York no fue el único. En Filadelfia, el Comité de Privados, un grupo de milicianos compuesto por artesanos de los "oficios inferiores", buscando imponer los términos de la elección de delegados para su convención constituyente, declaró que era "la felicidad de América que no haya rangos por encima de los hombres

\footnotetext{
15 Sentido común cosechó una enorme popularidad entre las clases trabajadoras en su conjunto, tanto por su lenguaje como por su llamado a la independencia. Sin embargo, entre ellas, sólo los artesanos reivindicaron y enraizaron el contenido republicano del panfleto como parte de su interés de clase. Ver nota al pie número 21 más adelante en el escrito.
} 
libres" y aconsejó elegir a aquellos portadores de "honestidad, sentido común y entendimiento llano" (citado en Foner, 1976).

Así, ya fuese citando Sentido común, brindando en su nombre o usándolo para presionar a las élites para que declararan la independencia, los artesanos se apropiaron de Thomas Paine y lo volvieron vocero de sus intereses y aspiraciones (Kaye, 2007). Una de las implicancias más destacadas de entender el panfleto en estos términos es que Sentido común no determinó la politización de las clases trabajadoras sino que es una expresión (incompleta) de la misma. A las clases trabajadoras sólo les hacía falta formular públicamente un proyecto independentista y Paine se los dio.

\section{"Un antídoto para el veneno popular" 16}

Para comienzos de 1776 no quedaba un solo colono que no hubiera oído hablar de Sentido común (Aptheker, 1965). Pero así como el panfleto fue alabado por las clases trabajadoras, fue temido por los whig. En un primer momento, la postura de John Adams respecto al escrito de Paine fue un tanto ambivalente. Por un lado, el furor de la argumentación independentista colaboraba con la causa por la cual él venía bregando en el Congreso Continental desde hacía meses. Sin embargo, al mismo tiempo, su educación en la Universidad de Harvard le había enseñado "que la elite de Nueva Inglaterra debía liderar y la multitud obedecer", así como le había instruido "desconfiar el entusiasmo religioso del Gran Despertar" y sumergirse en el racionalismo ilustrado (Hawke, 1971). Discutiendo con su esposa Abigail sus impresiones sobre Paine, Adams advirtió con recelo: "este autor parece tener ideas muy inadecuadas acerca de lo que es apropiado y necesario hacer para formar constituciones" (Adams, 1851). Sin duda, Paine y su proyecto de una legislatura de cámara única era algo muy "inadecuado" para élites coloniales que seguían discutiendo a puertas cerradas "un método para que las colonias insensiblemente se deslicen desde el viejo gobierno hacia una firme y apacible sumisión al nuevo" (citado en Countryman, 1985).

Para mayo de 1776, Adams habia concluido que "las rudimentarias e ignorantes nociones de un gobierno de una asamblea presentes en Sentido común harán más daño, separando a los Amigos de la Libertad, que todos los escritos tory juntos" (Adams, 1776). Decidido a contrarrestar los efectos del peligroso panfleto, Adams consintió a la publicación de Pensamientos sobre la forma de gobierno.

En un primer momento, este escrito fue un pedido encomendado a Adams por parte de dos delegados del Congreso Continental por Carolina del Norte, William Hooper y

16 Así define Adams a su panfleto en una carta a su amigo James Warren el 12 mayo de 1776: "Se ha publicado aquí, como Pensamientos sobre la forma de gobierno, un discurso para la Convención de Virginia como antídoto para el veneno popular. Léelo y atiende a la diferencia”. 
John Penn. Ambos habian sido designados para ayudar a redactar una posible constitución para la colonia y solicitaron a Adams (por separado) un "boceto" de sus opiniones sobre el tema. Cuando George Wythe17 (Virginia) y John Dickinson Sergeant ${ }^{18}$ (Nueva Jersey) vieron el manuscrito, solicitaron también una copia. Lo mismo sucedió con Richard Henry Lee quien fue finalmente el responsable de sugerir a Adams que publicara una de estas "cartas" a modo de panfleto (McCullough, 2001).

En Pensamientos sobre la forma de gobierno, Adams plasmó las bases para la adopción de un modelo republicano, lo cual él identificaba con "un imperio de la ley y no de hombres". Repleto de "controles y contrapesos", su plan hizo énfasis en que "un pueblo cuyo gobierno descansa en el unicameralismo no puede ser libre ni feliz" y por lo tanto defendió la adopción de una legislatura bicameral separada del ejecutivo y con un poder judicial independiente cuyos miembros podian retener los cargos "de por vida" (Adams, 1851). Adams desconfiaba de la habilidad de la "gente común" para gobernarse a sí misma y por lo tanto sus ideas estaban fuertemente influenciadas por la necesidad de contener la participación popular y limitar al mínimo su influencia dentro del gobierno. Entre las sugerencias del panfleto está, por ejemplo, demorar la reforma electoral a fin de evitar la confusión "y toda clase de actos perniciosos".

Al igual que en el caso de Paine con las clases trabajadoras, los planteos esbozados por Adams no eran ajenos a las elites coloniales. Ni tampoco a aquellas que gobernaban en Inglaterra. Su corte constitucionalista y las propuestas que, si bien no dejaban de ser republicanas, mantenían un marcado tinte conservador, pueden remitirse a la respuesta conservadora a la revolución de 1640. Los impulsos radicales de los levellers, surgidos en medio de la disputa entre el rey Carlos I y su Parlamento, si bien fueron exitosamente suprimidos por Oliver Cromwell, tuvieron un perdurable impacto en el pensamiento politico intelectual inglés (Meiksins Wood, 1991). Cromwell enfrentó a los levellers y defendió la supremacía de los hombres de propiedad contra la demanda radical de igualdad de derechos, apelando a convenciones y a la constitución inglesa como elementos fundantes de la propiedad privada y la desigual distribución de la riqueza en Inglaterra. Tres décadas más tarde, bajo los resultados de la Revolución Gloriosa de 1688, John Locke retomaría y puliría estos argumentos a fin de justificar las maniobras de los whig ingleses por alterar la sucesión monárquica (Meiksins Wood, 1991). Así, si bien el republicanismo mantuvo una teoria ambigua que no dejaba de generar desconfianza entre las clases dominantes (por sus posibles implicancias democráticas), retenía todo un acervo teórico impreso en la memoria de estas clases

\footnotetext{
17 Abogado perteneciente a una acaudalada familia de plantadores de Virginia.

18 Abogado, miembro del Congreso Provincial de Nueva Jersey.
} 
y que, con las debidas precauciones, podía retomarse y ponerse al servicio de una disputa transcontinental entre elites gobernantes. ${ }^{19}$

Pensamientos sobre la forma de gobierno circuló ampliamente en los primeros meses de 1776 y dado que se ajustaba a las necesidades políticas de las elites whig fue bien recibido entre conservadores y radicales. El modelo de Adams no solo ofrecía una forma de contrarrestar el tan temido "espíritu nivelador" sino que también justificaba la resistencia colonial contra los atropellos de la Corona y aseguraba que la independencia de Gran Bretaña no produjese cambios profundos en la organización social de las colonias. Los borradores de Thomas Jefferson para una constitución para Virginia siguen lineamientos parecidos, lo cual sugiere que este modelo de gobierno estaba asentándose en el imaginario de las clases altas coloniales tanto del Norte como del Sur (Lemisch, 1976). No es casualidad, por lo tanto, que Pensamiento sobre las formas de gobierno sirviera de base a la hora de redactar las constituciones federales de casi todos los estados salvo Pensilvania, Georgia y Vermont.

La recepción fue mucho más fría entre los artesanos, los cuales eran conscientes de las limitaciones que el bicameralismo podría imponer a sus aspiraciones. No por nada en aquellas colonias donde su capacidad de injerencia fue mayor triunfó la postura unicameral sugerida en Sentido común. Siendo Paine de la misma opinión (recordemos que había reprendido a Adams por el panfleto y lo había catalogado de "repugnante") dedicó una de sus Cuatro cartas sobre cuestiones de interés a desacreditar el modelo bicameral.

Adams había construido la legitimidad de su plan de gobierno en base a sostener que el mismo no hacía sino emular el republicanismo propio de la constitución inglesa, la cual admiraba profundamente (Adams, 1776). Por ende, Paine dirigió hacia alli su primera estocada. Si bien ya había criticado a la Constitución inglesa en Sentido común, su Carta IV redobló la apuesta: "La verdad es que los ingleses no tienen constitución" -declaró-. "Es sencillo comprender que los individuos, al concordar en erigir formas de gobierno (...) deben sacrificar parte de sus libertades para dicho propósito; y el objetivo particular de una constitución es dejar en claro a cuánto deben renunciar. En este sentido, es fácil ver que los ingleses no tienen constitución, porque ellos han renunciado a todo" (Paine, 1776).

De esto se desprendía que todo el sistema de "controles y contrapesos" y la división de poderes (tan importante para Adams) era más "una distinción de palabras que de cosas". "En cualquier gobierno no hay más que dos poderes, el poder para hacer

19 De hecho, el historiador Edmund Morgan (2006) ha postulado que las ideas sobre la soberanía popular fueron comúnmente utilizadas en las asambleas coloniales antes de 1760 por las elites contra los gobernadores reales si bien en todo momento fueron "cautelosos" para no invitar a una más amplia participación de la que les interesaba. El pueblo seguía siendo la corporización de una élite relativamente pequeña.

\section{anuario.}


leyes y el poder para ejecutarlas". El bicameralismo solo servía para

desatar la "petulancia" y "animosidad" entre los miembros de las cámaras (Paine, 1776).

Como puede verse, este intercambio entre Adams y Paine no se trata de una mera confrontación teórica entre modelos de gobierno, sino de una puja concreta sobre la preponderancia que viejas estructuras tendrian dentro de los nacientes estados americanos. El énfasis que cada autor puso, sea a favor de derribar o mantener en pie las pasadas jerarquías, hace visible la disputa que comenzaba a surgir entre clases populares defensoras de un radicalismo democrático y elites enarboladas tras los postulados de un republicanismo de corte conservador (Pozzi, 2012).

\section{Herencias culturales y planes de gobierno}

Tal como señalamos en los apartados anteriores, el hecho de que élites y artesanos hayan elegido reivindicar como propios los proyectos de gobierno esbozados por Adams y Paine nos sugiere una posible correlación entre propuestas políticas y sentimientos de clase vinculados a una específica herencia cultural. Haya sido deliberado o no (probablemente una combinación de ambos), Adams y Paine apelaron a tradiciones y valores aprendidos a la hora de formular sus proyecciones.

La presencia de jerarquías como eje organizador de la sociedad colonial y la heterogeneidad de grupos que la escala social englobaba hace dificil que podamos referirnos a un antagonismo de clase con las características que este tendría en el marco de relaciones sociales de producción capitalistas. Durante el siglo XVIII, los individuos se veían a sí mismos conectados verticalmente bajo redes de poder o dependencia, por lo que eran más proclives a tener noción de quienes se encontraban por encima o por debajo de su status que de posibles lazos horizontales (Wood, 1991).

Esto no implica, sin embargo, que debamos dejar de referirnos a los grupos en disputa como clases sociales. Como señala Alfred Young (1976), hay suficiente evidencia para sugerir que el concepto "clase" sigue siendo central para explicar las relaciones sociales en la última etapa del período colonial norteamericano. A tal punto esto es así que muchas veces conflictos de clase previos a la Independencia jugaron un rol determinante en las alianzas y enfrentamientos que atravesaron la resistencia a la Corona británica. Sea profundizando o resolviendo latentes animosidades entre las clases coloniales, lo que el proceso revolucionario permitió fue que distintas clases sociales agudizaran la percepción de sus intereses en 
conflicto, y lo tradujeran en un accionar concreto. En esa contraposición, nosotros vemos gestarse clases y distintivas formas de conciencia. ${ }^{20}$

En el caso de las elites, la percepción de sí misma estaba fuertemente arraigada en distinciones sociales con una marcada impronta aristocrática donde los privilegios asociados a la riqueza y la educación eran consecuencia de un status elevado dentro de la jerarquía social (Thompson, 1989). El espíritu nivelador de la era revolucionaria los estimuló a cerrar filas y relegar su competencia a las necesidades de retener el poder "entre los suyos" (Lynd, 1967).

En cuanto a las clases trabajadoras, lo que comenzó a estrecharse es un sentido de "ellos" y "nosotros" donde la distinción la trazaba el valor asociado al trabajo y la utilidad social del mismo. No todos los grupos lograron "descubrirse a sí mismos" al mismo tiempo ni en la misma medida. Entre ellos, los artesanos fueron quienes más se acercaron a desarrollar un interés de clase. ${ }^{21}$ Sin embargo, la crisis económica desatada por la guerra revolucionaria y la introducción del capitalismo a fines de la década de 1780 supusieron una traba a su desarrollo.

Podemos ver este proceso de construcción en las publicaciones de Adams y Paine. Un buen ejemplo son las razones que llevaron a cada uno a publicar en el anonimato. Paine retuvo su nombre al público, en primer lugar, por las mismas razones por las que Benjamin Rush lo consideró un candidato ideal para escribir el panfleto: era un extraño en Filadelfia, de origenes modestos y sin conexiones. En segundo lugar, pues, como anunció en el prólogo de la tercera edición, "Quién es el autor de esta producción, es totalmente innecesario para el público pues el objeto de su atención es la doctrina, no el hombre" (Foner, 1945).

En una sociedad definida por jerarquías, como lo era la colonial, renombre y reputación eran privilegios circunscriptos a aquellas clases ubicadas en la cima de la escala social. Reticentes a poner su status en juego durante los actos de resistencia al dominio británico, muchas veces las élites whig estimularon la participación de las clases trabajadoras apelando a su "anonimato" como garantía de impunidad. Tal como Rush relata en su autobiografia: "Le sugeri (a Paine) que no tenía por qué temer a las repercusiones a las que una publicación así podían exponerlo, podia vivir en cualquier parte, pero yo, dada mi profesión y mis

20 Siguiendo a E. P. Thompson (1989), "las clases no existen como entidades separadas, que miran en derredor, encuentran una clase enemiga y empiezan luego a luchar. Por el contrario, las gentes se encuentran en una sociedad estructurada en un momento determinado [...], experimentan la explotación [...], identifican puntos de interés antagónicos, comienzan a luchar por estas cuestiones y en el proceso de lucha se descubren como clase, y llegan a conocer este descubrimiento como conciencia de clase".

${ }^{21}$ Diversos factores colaboraron a ello. El conjunto de tradiciones y costumbres de larga data que los artesanos compartian, su sentido de pertenencia al oficio (expresado en la formación de sociedades y mutuales) y el trabajo cooperativo (tanto en el taller como entre distintos oficios). Todo esto bajo el contexto de la crisis revolucionaria aceleró el proceso de formación de los artesanos en términos de clase. Paine colaboró a este proceso al darles un programa político bajo el cual se veían sintetizadas sus aspiraciones. 
conexiones estaba atado a Filadelfia" (Rush, 1948). Al igual que

muchos marineros y artesanos, Paine encontró motivaciones propias para acceder al pedido de estos hombres de influencia y al igual que muchos como él, la experiencia que su consentimiento desencadenó, modificó la percepción de ese "anonimato". Al declarar que lo importante era la doctrina y no el hombre, Paine hizo que su anonimato dejara de ser la consecuencia de su status social y pasara a convertirse en una reivindicación personal. Eso es lo que la revolución hizo con las clases populares, construir dentro de ellas un sentido de importancia que las igualaba con sus "mejores" (Young, 1981).

John Adams es un caso por completo distinto. Miembro del Congreso Continental por Massachusetts desde 1774, nuestro abogado fue sumamente cauto a la hora de anunciar su proyecto de gobierno. El primer boceto de la carta a Hooper, Adams la dedicó a Richard Henry Lee en noviembre de 1775, pero recién en abril del año siguiente consintió a su publicación. Y no fue algo de lo que alardeó en el Congreso Continental hasta que se acordó declarar la independencia. Es decir, en un momento donde las elites coloniales seguían insistiendo con la reconciliación, declararse abiertamente a favor de una nueva forma de gobierno era una pobre maniobra política. Su prudencia se enmarca en las disputas al interior de una clase que monopolizaba el poder político y económico pero que aún buscaba definir el lugar que ocuparía tras la independencia.

Tal como estos ejemplos muestran, estamos ante clases sociales que fueron construyéndose a sí mismas a lo largo de la Revolución. A medida que lo hicieron, emergieron rispideces entre ellas lo cual dio lugar a confrontaciones. Una interpretación integral de los panfletos no puede perder de vista esta dinámica porque la lucha entre Adams y Paine no se trató de un episodio aislado. Por el contrario, desde sus origenes con la resistencia a la Ley de Sellos, la crisis revolucionaria estuvo plagada de acontecimientos donde, como lo ilustró Staughton Lynd (1968), "la multitud fue llamada al escenario para oficiar de marioneta y terminó quedándose como protagonista". Fueron las clases trabajadoras las que volvieron a la independencia estadounidense una revolución (Kaye, 2007). No es casualidad, por lo tanto, que haya sido Thomas Paine, un artesano devenido en escritor, quien haya hecho público el primer grito a favor de la independencia como tampoco que haya sido la presión ejercida por Sentido común la que motivó la necesidad de Adams por contrarrestarlo.

Por otro lado, para entender la dinámica de estos sujetos en formación hay que advertir que las clases no se construyen a sí mismas a partir de la nada sino que traen consigo experiencias, lealtades y valores que son puestos en juego en el proceso de construcción (Torre, 1990). El contenido de los panfletos está repleto de este proceso donde viejas tradiciones son puestas al servicio de nuevos ideales y ayudan a que la clase se haga a sí misma. 
Tomemos Sentido común. Si lo dividimos según los temas centrales que Paine trata, podremos ver que todos son referibles a la cultura de las clases populares de la época. Por ejemplo, la ridiculización de la realeza. Según Paine, si quitáramos "el velo de antigüedad" que mantiene "a oscuras los orígenes de los reyes", probablemente encontrariamos que "el primero de ellos no fue algo más que el principal rufián de una banda de criminales" (Foner, 1945).

Paine no solo se burla de la realeza, deliberadamente busca humillarla. Su forma de proceder nos remite a uno de los rituales populares más difundidos durante el siglo XVIII: el "castigo popular". En una época donde los sectores subalternos estaban excluidos de participar en política, la gente común debía apelar a canales "extraoficiales" para hacer oír sus demandas y aspiraciones. El "castigo popular" era uno de ellos. Durante estos rituales, la multitud oficiaba como una suerte de autoridad moral que llevaba adelante la voluntad de la mayoría contra individuos que (se consideraba) habian actuado contra el bienestar de la comunidad. Si bien la violencia entraba en juego a la hora de capturar y exponer al infractor, el verdadero objetivo no era la agresión sino la humillación pública.

Sentido común somete al rey Jorge a esta humillación. Lo describe como "el real bruto de Inglaterra" y lo acusa de estar actuando contra el bienestar general de sus súbditos al otro lado del Atlántico (Foner, 1945).

Los argumentos utilizados para llevar adelante esta humillación también hacen eco de la cultura popular. Por un lado, está la constante homologación entre el rey y un (mal) padre, la cual nos sugiere que actitudes y formas de expresión paternalista eran comunes en el trato jerárquico entre clases. Más bien, nos sugiere la conciencia de los estratos inferiores de que asi se comportaban con ellos los superiores. Cuánto las clases trabajadoras reverenciaban a quienes tenian por encima es discutible. La deferencia tenía componentes de respeto por la autoridad, pero la conveniencia y el disimulo jugaban un papel igual de determinante. Y como señala Gary Nash (1979), en tiempos de crisis, tales como el periodo revolucionario, esa deferencia podía romperse. En Sentido común podemos apreciar esta deferencia ya rota: "Los hombres que se ven a sí mismos como nacidos para gobernar y al resto como nacidos para obedecer, pronto se vuelven insolentes. Seleccionados del resto de la humanidad, sus mentes son fácilmente envenenadas por un sentido de importancia" (Foner, 1945).

Por otro lado, cabe destacar que Paine siempre describe al rey como un inútil: "Si indagamos acerca de cuáles son los deberes de un rey, encontraremos que en muchos países no los tiene; y luego de malgastar sus vidas sin obtener por ello placer o beneficios para la nación, se retiran de la escena y dejan a su sucesor para que cargue con la misma ociosa rutina" (Foner, 1945). Esto nos remite a valores propios de la tradición artesana, en particular al sentido de orgullo que los mecánicos derivaban de la utilidad social de su oficio. Para ellos, el trabajo no era 
únicamente una actividad económica sino también un acto moral y

social. Dado que en las sociedades preindustriales la comunidad dependía del trabajo calificado para producir bienes y servicios, una vida de trabajo productivo representaba la contribución del artesano al bienestar de su sociedad (Schultz, 1990).

A su vez, este sentido de orgullo estaba imbricado con una noción de "competencia", entendiendo esta como aptitud, es decir, que el artesano fuera "competente" a la hora de desempeñar su oficio. El resultado del buen ejercicio de la competencia era la prosperidad, sinónimo de "independencia". Esta no significaba acumulación de riqueza o movilidad social sino "la habilidad para mantenerse a uno mismo por medio de su trabajo sin tener que recurrir al Estado o a la caridad" (citado en Nash, Smith \& Hoeder, 1983).

El llamado de Paine a la independencia pertenece a este ámbito de identificación. Frases como "el interés de América es que provea para sí misma" o "...deberíamos estar ansiosos de alcanzar (la independencia) en términos seguros, firmes y honorables" (Foner, 1945) de seguro resultaron familiares para los artesanos, en un contexto donde el movimiento de no importación había realzado sus roles como proveedores de la comunidad.

Al contrario de los artesanos y demás trabajadores -todos ellos honestos y con un sentido de pertenencia al colectivo social- el rey era un "ocioso". No solo su cargo carecía de una utilidad sino que además la monarquía se lo obstaculizaba: "Hay algo extremadamente ridículo en la composición de la monarquía; primero priva al hombre de las fuentes de información y luego lo empodera para actuar en casos donde el más elevado juicio es requerido" (Foner, 1945).

Estos ejemplos ponen en evidencia cuestiones planteadas por E.P. Thompson (1995) para el caso de Inglaterra. En primer lugar, que las costumbres (y la cultura en general) son "un campo de cambio y contienda". No son algo estático sino algo que está en constante flujo dentro de un determinado equilibrio de relaciones sociales bajo un contexto específico. En segundo lugar, la cultura tiene una funcionalidad tanto práctica como racional dentro de la vida cotidiana de los individuos atravesados por ella.

Los puntos de contacto entre la tradición artesana y Sentido común testimonian como hábitos y costumbres remontables a la Inglaterra del siglo XVII fueron puestos al servicio de nuevos ideales al otro lado del Atlántico. ${ }^{22}$ Para ser

\footnotetext{
${ }^{22}$ Los aspectos religiosos en Sentido Común, exceden las intenciones del presente escrito, sin embargo, las continuas alusiones religiosas hechas por Paine pueden comprenderse imbricadas con un "evangelismo igualitario" o "radicalismo religioso", propio de la cultura popular de la época. Véase el Capítulo 4 de Vikki J. Vickers “The origins and significance of Paine's religious beliefs” (Vickers, 2006).
}

\section{anuario.}


funcionales a esta nueva realidad, debieron ser adaptados y resignificados bajo la experiencia cotidiana de los sujetos que los portaban. Esto implica que Thomas Paine no solo logró sintetizar un conjunto de valores y formas de comportamiento heredado sino que en tanto se valió de ellos para llevar adelante la causa de la independencia, creó algo nuevo. Por eso Sentido común es un salto de calidad en la tradición artesana y pasó a ser la expresión más acabada del radicalismo artesanal en el siglo XVIII (Pozzi, 2012).

En cuanto a John Adams, la larga tradición a la que este pertenecía, de al menos dos siglos de antigüedad, ya había logrado traducirse en términos ideológicos y funcionaba legitimando la estructura de poder politico vigente en Inglaterra (Morgan, 2006). Es por eso que componentes centrales de la teoría política whig clásica sobresalen entre las líneas de Pensamientos sobre la forma de gobierno (Nash, 1979).

Sin embargo, podemos ver la correlación entre tradición y expresión política en propuestas concretas de su plan de gobierno. Tanto la educación intelectual como la tradición cultural en la que Adams se formó le enseñaron que el gobierno era un espacio que debía mantenerse ajeno a la participación de los sectores sociales menos favorecidos ya que éstos, al estar desprovistos de propiedad (y educación), carecian de las cualidades industriosas y frugales que definian a las clases gobernantes (citado en Foner, 1976).

La "revolución", para Adams, era fundar un gobierno inmune a "la tiranía de la mayoria" a través de la adopción de una asamblea bicameral donde la cámara alta (cargos no electivos) mantuviera en jaque las propuestas elaboradas en la cámara baja (cargos electivos). Esto pone en evidencia que la justicia, para Adams y su clase, se define como orden. Y como un espacio donde las leyes se disponen pero es el poder que las ejecuta quien retiene la última palabra. Es decir, la minuciosidad del modelo de Adams nos marca tanto la búsqueda de un sistema de gobierno que perpetuara a las élites en el poder como la desconfianza a la hora de permitir la incidencia de las clases trabajadoras en el terreno político. Esto devino en la construcción de una estructura de gobierno que no sólo aseguró la continuidad de desigualdades sociales a nivel institucional, sino que también contribuyó a su permanencia (Lemisch, 1976).

Pese a ello, las particularidades de la crisis revolucionaria advirtieron a Adams dos cosas. En primer lugar, que el consenso popular era indispensable para mantener en pie la resistencia a Gran Bretaña. Luego, que las clases populares estaban más que dispuestas a confrontar con el liderazgo de las elites cuando estas no acataban sus reclamos. Por ello, Adams tuvo presente la necesidad de crear canales institucionales de participación popular si bien se aseguró de mantener esa participación popular controlada. El bicameralismo servía bien a ambos fines. 
Por último, si prestamos atención a las razones que Adams enumera para manifestarse contra el unicameralismo, veremos que muchos de sus argumentos se corresponden con la percepción peyorativa que las elites tenían de las clases trabajadoras. Como explica Gary Nash (2006), a lo largo de la historia las clases altas le han temido a la "multitud". La fuente de estos miedos nace de entender a las masas como colectivos irracionales, avivados por agitadores hacia paroxismos violentos que no discriminaban entre sus víctimas. Una vez liberada, la "muchedumbre sucia e irreflexiva" era capaz de cualquier cosa. No es casualidad, por lo tanto, que entre las razones principales que Adams enumera para rechazar el modelo unicameral se encontrara que "una única asamblea está expuesta a los vicios, las locuras y las flaquezas de los individuos; está condicionada a sus cambios de humor, arranques pasionales, saltos de entusiasmo, parcialidades, prejuicios $\mathrm{y}$, consecuentemente, produce resultados apresurados y juicios absurdos. Todos estos errores deben ser corregidos y los defectos complementados por alguna forma de poder dominante" (Adams, 1851). En otras palabras, el modelo unicameral llevaría a la "muchedumbre" al gobierno dejando a las élites a merced de sus vicios e irracionales ambiciones.

\section{Reflexiones finales}

Para fines de julio de 1776 las insurgentes colonias británicas en Norteamérica, recién devenidas en estados independientes, debieron enfrentar la vertiginosa tarea de erigir constituciones. Durante once años, gente de todos los estratos, desde terratenientes hasta marineros, contribuyeron a derrocar a la monarquía británica. Ahora debian emplear esas energias en fundar gobiernos estaduales.

La ambigüedad del igualitarismo de Jefferson permitió que tanto elites como clases trabajadoras se sintieran representadas en su declaración, pero el choque de intereses fue inevitable. Tan solo un mes antes de que la declaración fuese distribuida al público, el Comité General de Mecánicos había solicitado al Congreso Provincial que los delegados para el Congreso Continental fueran elegidos popularmente, recibiendo por respuesta que el Comité no era más que una "asociación voluntaria" de artesanos y que, por lo tanto, carecía de cualquier "autoridad para opinar sobre los asuntos públicos del tiempo presente" (citado en Lynd, 1967).

Con la independencia, las contradicciones del proceso revolucionario no se resolvieron, sino todo lo contrario. Cuando la heterogeneidad de grupos que lo protagonizaron dieron un paso al frente, tuvieron que luchar por volcar sus demandas en la redacción de las leyes fundamentales para los nacientes estados. 
Ninguno debió construir a partir de la nada. Tenían una cultura y valores a los cuales recurrir, experiencias concretas de organización y resistencia como ejemplo, y dos panfletos que ya habian moldeado una estructura de gobierno acorde a sus aspiraciones. Por lo tanto, recurrieron a ellos.

Entre las primeras constituciones redactadas nos encontramos con que la de Virginia se inspiró en el plan de John Adams, mientras que la de Pensilvania emuló los "consejos" esbozados por Thomas Paine. Luego se sancionaron las restantes. En total, nueve constituciones terminaron por expresar un "republicanismo conservador" con una marcada impronta antipopulista. Hicieron hincapié en una legislatura bicameral, cargos por designación para sus ejecutivos y requisitos de propiedad para los votantes. Las tres constituciones restantes defendieron la democracia radical painita y por lo tanto adoptaron una única asamblea sobre el principio de que "cualquier hombre, incluso el más iletrado, es tan capaz de ocupar un cargo como una persona que haya recibido el beneficio de la educación" (citado en Lemisch, 1976). Las elecciones serian anuales, controladas y equilibradas por la misma gente para quienes las puertas de la Sala de Asambleas debian estar siempre abiertas. Así, las constituciones federales surgidas durante la guerra revolucionaria continuaron la disputa planteada entre Paine y Adams en sus panfletos.

Lo que hemos podido apreciar es que el diálogo entre ambos autores fue más allá de una confrontación entre puntos de vistas expresados en tinta y papel. Sus producciones son huellas a través de las cuales podemos reconstruir la turbulencia política y la ebullición de ideas que la sociedad colonial norteamericana venía vivenciando desde 1774. La retórica y las propuestas de los panfletos nos hablan de las características del clima insurreccional de la época y de la disputa entre clases sociales a fin de asegurar que su desenlace satisficiera las demandas que los llevaron a involucrarse en un primer momento.

Así, los panfletos analizados sintetizan las tensiones dentro de la naciente sociedad estadounidense entre democracia radical y república conservadora (Pozzi, 2012). Tensiones que, como puede verse en la redacción de las constituciones ocurridas después de julio de 1776, no murieron con la independencia ni quedaron en un mero intercambio de palabras entre un abogado y el hijo de un artesano. La aplicación concreta de sus propuestas y la reivindicación que generaciones futuras harian de ellos las mantuvieron con vida.

A su vez, los continuos ataques que constituciones como la de Pensilvania sufrieron por parte de las élites con posterioridad a 1776 (la misma logró ser reemplazada por un modelo conservador en 1790), nos anticipan la marginación que sufririan las ideas painitas en el marco de la naciente política estadounidense. Quedaría a cargo de las organizaciones artesanas seguir reivindicando su radicalismo democrático y brindando en nombre del "honesto Tom Paine". 


\section{Bibliografia}

Adams Papers Digital Edition, Massachusetts Historical Society. Recuperada de https://www.masshist.org/publications/adamspapers/index.php/view/ADMS-06-04-02-0026-0002\#sn=4

Adams, J. (1851). Thoughts on Government, Applicable to the Present State of the American Colonies. En Adams, C. (comp.); The works of John Adams, second president of the United States with a life of the author, notes and illustratios Vol. IV. Boston: Little \& Brown.

Adams, J. (1875). En Adams, C. (comp.); Familiar Letters of John Adams and his Wife Abigail Adams during the revolution. Cambridge: The Riverside Press.

Aptheker, H. (1965). Historia de la Revolución Norteamericana. Buenos Aires: Editorial Futuro.

Countryman, E. (1985). The American Revolution. Nueva York: Hilland Wang.

Cotlar, S. (2011). Tom Paine's America: The Rise and Fall of Transatlantic Radicalism in the Early Republic. Virginia: University of Virginia Press.

Foner, E. (1976). Tom Paine and Revolutionary America. Londres: Oxford University Press.

Freeman Hawke, D. (1971). Benjamin Rush: Revolutionary Gadfly. Nueva York: The Bobbs-Merrill Company Inc.

Freeman Hawke, D. (1992). Paine. Nueva York: W.W. Norton.

Fruchtman Jr., J. (1996). Thomas Paine: Apostle of Freedom. Village Station: Four Walls Eight Windows.

Fruchtman Jr., J. (2009). The Political philosophy of Thomas Paine. Baltimore: The John Hopkins University Press.

Hobsbawm, E \& Pochtar, R \& Beltrán Ferrer, J. (1999). Gente poco Corriente: resistencia, rebelión y jazz. Barcelona: Crítica. 
Kaye, H. J. (2007). Thomas Paine and the Promise of America: A History \& Biography. Nueva York: Hill and Wang.

Larkin, E. (2005). Thomas Paine and the Literature of Revolution. Nueva York: Cambridge University Press.

Lemisch, J. (1976). La Revolución Americana vista desde el Fondo. En Bernstein, B. J. (comp.); Ensayos Inconformistas sobre los Estados Unidos: Hacia un nuevo pasado. Barcelona: Península.

Linebaugh, P. (Ed.) (2009). Peter Linebaugh presents Thomas Paine: Common Sense, The Rights of Man and Agrarian Justice. Londres: Verso.

Linebaugh, P. (1982). All the atlantic mountains shook. En Labour/Le Travail, Vol. 10. Recuperado de https://www.jstor.org/stable/25140140?seq=1

Lynd, S. (1967). Class Conflict, Slavery and the United States Constitution. Nueva York: The Bobbs Merrill Company.

Lynd, S. (1968). Intellectual Origins of American Radicalism. Nueva York: Pantheon Books.

Mastrángelo, M. (2009). Oralidad y cultura radicalizada en el interior de la provincia de Córdoba, Argentina. Los casos de San Francisco y Río Cuarto en las décadas de 1930 y 1940. Antitesis, Vol 2, $\mathrm{N}^{\circ} 3$. Recuperado de https://dialnet.unirioja.es/servlet/articulo?codigo $=5026809$

McCullough, D. (2001). John Adams. Nueva York: Simon \& Schuster.

Morgan, E. (2006). La Invención del Pueblo: El surgimiento de la Soberanía Popular en Inglaterra y Estados Unidos. Buenos Aires: Siglo XXI Editores.

Nash, G. (1979). The Urban Crucible: The Northern Seaports and the origins of the American Revolution. Estados Unidos: Harvard University Press.

Nash, G. (2006). The unknown American Revolution: the unruly birth of democracy and the struggle to create America. Londres: Penguin Books.

Nash, G. \& Smith, B. G. \& Hoeder, D. (1983). Labor in the era of the American Revolution: An Exchange. Labor History, Vol $24 \mathrm{n}^{\circ} 3$. Recuperado de https://www.tandfonline.com/doi/abs/10.1080/00236568308584721?journa $\underline{1 \text { Code }=\text { clah } 20}$

Paine, T. (1945). Common Sense. En Foner, P. S. (Comp.) The Complete Writings of Thomas Paine Vol I. Nueva York: The Citadel Press. 
Paine, T. (1776) "Four Letters on interesting subjects" en Thomas Paine National Historical Association consultado en https://www.thomaspaine.org/recently-discovered/four-letters-on-interestingsubjects.html.

Pozzi, P. (2017). Thomas Paine: el revolucionario ignorado. Recuperado de http://www.laizquierdadiario.com/Thomas-Paine-el-revolucionario-ignorado.

Pozzi, P. (2012). Thomas Paine: La Democracia Radical vs la República Conservadora. Huellas de Estados Unidos: Estudios y Debates desde América Latina, $\quad \mathrm{N}^{\circ}$ 3, $\quad$ septiembre 2012 . Recuperado de http://www.huellasdeeua.com/index.html

Raphael, R. (2001). A people's history of the American Revolution: How common people shaped the fight for independence. Nueva York: W.W. Norton.

Rediker, M. (1982). Good hands, Stout Heart and Fast Feat: The history and culture of Working People in Early America. Labour/Le Travail. Recuperado de https://www.jstor.org/stable/25140141

Rush, B. (1948). The Autobiography of Benjamin Rush: His "Travels Through Life". London: Oxford University Press.

Schultz, R. (1993). The Republic of Labor: Philadelphia Artisans and the politics of class, 1720-1830. Nueva York: Oxford University Press.

Schultz, R. (1990). The small-producer Tradition and the moral origins of Artisan Radicalism in Philadelphia 1720-1810. Past \& Present, N 127. Recuperado de https://www.jstor.org/stable/650943

Thompson, E. P. (1995). Costumbres en común. Barcelona: Crítica.

Thompson, E. P. (1989). Tradición, revuelta y conciencia de clase. Barcelona: Crítica.

Torre, J. C. (1990). Acerca de los estudios sobre la historia de los trabajadores en la Argentina, Anuario del IEHS, Vol V. Tandil: Universidad Nacional del Centro de la Provincia de Buenos Aires. Recuperado de anuarioiehs.unicen.edu.ar

Vickers, V. (2006). My Pen and My Soul Have Ever Gone Together: Thomas Paine and the American Revolution. Nueva York: Routledge. 
Wood, G. S. (1991). The Radicalism of the American Revolution. Nueva York: Vintage Books.

Young, A. F. (2006). Liberty Tree. Ordinary People and the American Revolution. Nueva York: New York University Press.

Young, A. F. (1981). George Robert Twelves Hewes (1742-1840): A Boston Shoemaker and the Memory of the American Revolution. The William and Mary Quarterly: A Megazine of Early American History, 1981. Recuperado de https://www.jstor.org/stable/1918907?seq=1

Young, A. F. (1976). The American Revolution. Illinois: Northern Illinois University Press.

Recibido: 3 de abril de 2021 Aceptado: 15 de mayo de 2021 Versión Final: 26 de junio de 2021 